\title{
Patterns of bronchial challenge testing in Canada
}

\author{
Rémi Thériault $\mathrm{BA}^{1}$, Amir Raz $\mathrm{PhD}^{1,2,3,4}$
}

R Thériault, A Raz. Patterns of bronchial challenge testing in Canada. Can J Respir Ther 2018;54(2):41-47. doi: 10.29390/cjrt-2018-006.

\begin{abstract}
Background: Bronchial challenge testing (BCT) measures airway hyperresponsiveness; asthma guidelines recommend using BCT when symptoms manifest despite normal spirometry. Improper application of these guidelines commonly results in the misdiagnosis of asthma. Yet, statistics concerning BCT remain largely obscure. The current paper addresses this gap and explores how various health variables may elucidate adherence to asthma guidelines and patterns of BCT across Canadian provinces.

Methods: Using the Access to Information Act, medical financial claims for BCT (or equivalent procedures) were requested from each of the Canadian provinces and territories. Based on the available information (from provinces only), correlations between frequency of BCT claims and medical demographics (e.g., prevalence of respirologists, health expenditures) are reported.

Results: Controlling for population or for people with asthma, physicians from Québec claim four times more BCT per year than those in other provinces; physicians from Alberta close to eight-fold fewer. The number of respirologists per capita and BCT per capita correlated moderately, $r(132)=0.582$, $p<0.001$, [95\% CI 0.421, 0.716]. Excluding “outliers" (i.e., British Columbia, Alberta, and Saskatchewan) greatly strengthened this correlation, $r(87)=$ $0.930, p<0.001,[95 \%$ CI $0.883,0.958]$.

Discussion: These findings demonstrate that provinces vary in their use of BCT. This result seems to stem, at least in part, from differences in the prevalence of respirologists. Interestingly, geographic region appears to wield a strong influence; in the correlation between number of tests and number of respirologists, physicians from Western provinces (i.e., Alberta, Saskatchewan, and British Columbia) administered fewer tests than their Eastern colleagues. Given the association between inadequate application of BCT and misdiagnosis of asthma, physicians should pay special attention to the Canadian guidelines when considering an asthma diagnosis.
\end{abstract}

Key Words: bronchial challenge testing; asthma; misdiagnosis; medical financial claims; guidelines; respirologists

\section{INTRODUCTION}

Existing asthma guidelines [1-6] recommend that physicians confirm the diagnosis of asthma with objective pulmonary function testing (PFT) measures [7], including, but not limited to, spirometry [8] and nonspecific bronchial challenge testing (BCT) [9]. This practice helps to reduce misdiagnosis and its societal and personal costs [10]. Without PFT, physicians risk over-diagnosing or under-diagnosing asthma by approximately 30\% [11-16] and 20\% [15-18], respectively. Consequently, an editorial in the Canadian Medical Association Journal [19] stated that "Failure to make the diagnosis of asthma objectively is unacceptable... Physicians who do not use spirometry for their asthma patients should not be managing asthma," (p. 1099), although some disagree [20]. And yet, the little available documentation concerning frequency of PFT suggests that Canada scantily meets its asthma guidelines [2]. One study [21] reported only $54 \%$ of individuals diagnosed with asthma ever had PFT; only $49 \%$ of general practitioners and $46 \%$ of physicians reported using PFT. In a study looking at over-diagnosis [12, 22], only $49 \%$ of patients went through spirometry on the initial diagnosis of asthma. Two other studies revealed that only $43 \%$ and $52 \%$ of diagnosed individuals received PFT in Ontario [23] and Nova Scotia [13], respectively. Overall, these findings propose that Canadian physicians resort to PFT in a suboptimal fashion [24].

In the presence of symptoms but normal spirometry, Canadian guidelines [2] recommend measuring airway hyper-responsiveness via BCT [9]. A rough estimate of the percentage of people requiring BCT can be formed from the number of patients that show normal spirometry despite reporting respiratory symptoms (although alternative methods besides BCT can also be used to investigate asthma given normal spirometry, such as bronchodilator response [25], peak flow monitoring and trial of therapy [26], and sputum induction and fractional exhaled nitric oxide [27]). The NHANES III study [28], based on a US sample of more than 16,000 individuals, estimated that more than $85 \%$ of adults older than 24 years of age with respiratory symptoms (including diagnosis of asthma) will have normal lung function as measured by spirometry. Moreover, when specifically investigated for asthma, between 55\% [29] and 67\% [30] of children and approximately $34 \%$ [31] of adults older than 50 years will typically show normal spirometry. In one study [32] of adults with symptoms of obstructive pulmonary disease, $63 \%$ had normal spirometry ( $80 \%$ excluding chronic obstructive pulmonary disease); BCT later identified asthma in $47 \%$ of individuals with normal spirometry. Despite these abovementioned data concerning normal spirometry, to the best of our knowledge, the only source documenting BCT is a survey that relied on a small convenience sample [33]. This survey estimated the application of BCT in the province of Québec to approximate 5150 tests per year. Otherwise, no systematic data are readily obtainable on the use of BCT within Canada. This paper presents patterns of BCT across Canada, speculates on potential factors influencing its use, and contextualizes these trends in relation to the Canadian asthma guidelines. This work will contribute to bring a unique perspective to better understand, and eventually address, the misdiagnosis of asthma in Canada.

\footnotetext{
${ }^{1}$ Faculty of Medicine, McGill University, Montréal, QC, Canada

${ }^{2}$ Institute for Community and Family Psychiatry, Montréal, QC, Canada

${ }^{3}$ The Lady Davis Institute for Medical Research at the Jewish General Hospital, Montréal, QC, Canada

${ }^{4}$ Institute for Interdisciplinary Behavioral and Brain Sciences, Chapman University, Irvine, CA, USA

Correspondence: Professor Amir Raz, 4333 Cote Ste. Catherine Rd., Montreal, QC, H3T 1E4, Canada. Tel.: 514-340-8210, Fax: 1-514-340-8124. E-mail: amir.raz@mcgill.ca
} 


\section{METHOD}

Using the Access to Information Act, medical financial claims for BCT (or equivalent procedures; see Supplementary File $1^{1}$ for an overview of how each province labels BCT) were requested from each of the Canadian provinces and territories (see Supplementary File $2^{1}$ for exclusions and details on data format and handling). Time-series data were obtained from 9 provinces: spanning the most recent year on record (2014-2015) and going back to the earliest year reporting was available (2000-2001). Based on the available information (see Supplementary File $3^{1}$ ) an exploratory effort was performed to: $(i)$ examine national and provincial trends and frequencies of (insurance) reimbursement records for BCT; (ii) normalize numbers of BCT claims per 10,000 people based on population estimates from Statistics Canada [34] and per 1000 individuals with asthma [35]; and (iii) correlate the number of BCT claims with the prevalence of professionals (i.e., respirologists, allergists, internists, and general practitioners) based on estimates from the Canadian Medical Association Masterfile [36]. The correlation between the number of BCT claims and various health variables were also investigated (e.g., population with asthma, location of physician training, and health expenditures). For all computations, SPSS version 24 and bootstrapping (resampled 2000 times) were used to obtain confidence intervals for all correlations. Bootstrapping is a commonly used technique that simulates multiple potential samples based on the available data to provide estimations that do not rely on the classical assumptions of statistical inference.

\section{Could BCT be over-prescribed?}

From consultations with asthma experts who harbour decades-long operational insights into the diagnosis of asthma in Canada (Dr. Ronald Dandurand, written communication, May 2016; Dr. André Cartier, written communication, August 2016; Dr. Jean-Luc Malo, written communication, July 2016; Dr. James Martin, written communication, August 2016; Dr. Larry Lands, written communication, May 2016; Dr. Francisco Noya, written communication, September 2016) emerged the question of whether BCT is under- or over-prescribed across the nation. To this aim, an informal, "back-of-the-envelope" calculation was performed using simplified assumptions-to be taken with a pinch of salt. To form a rough provincial estimate of the percentage of asthmatics who had BCT over the past 15 years (the period of available data), the total number of claims throughout 2000-2014 was divided by the number of people with asthma in 2014 (the most comprehensive figures available from Statistics Canada) [35] for each individual province. In sum, this procedure highlights the total number of BCT claims as a percentage of the number of asthmaticsa rough index to the number of asthmatics who received BCT.

\section{RESULTS}

Figure 1 displays data for the number of medical claims for BCT. Two provinces markedly contrast with the others when controlled for population or alternatively for population with asthma: physicians from Québec perform four times more tests per year (the highest ratio), whereas physicians from Alberta perform nearly eight-fold fewer tests (the lowest ratio). Table 1 depicts correlations and confidence intervals of BCT claims per capita. Correlation analyses revealed a moderate relationship between number of respirologists and BCT claims (Model 1 in Table 1 and Figure 2). A visual inspection of Figure 3 suggests that Alberta, British Columbia, and Saskatchewan differ considerably from the rest of the other provinces in terms of their BCT and respirologist ratios. A second, exploratory correlation analysis without these provinces was therefore performed (Model 2 in Table 1), which greatly strengthened the correlation between BCT claims and respirologists. In general, these "outliers" seem to cluster on the West coast (Figure 4). Geographic region only seems to meaningfully modulate the correlation between BCT claims and respirologists (Table 1). Finally, Figure 5 shows clear differences among provinces in the estimated percentage of asthmatics with BCT over the past 15 years.

${ }^{1}$ Supplementary data are available with the article through the journal Web site at https://www.cjrt.ca/wp-content/uploads/wpdmdl695.pdf

\section{DISCUSSION}

Compared with other provinces, the number of tests in Québec is four times higher; in Alberta, it is eight-fold lower-acknowledging population size and asthma rates. The higher rate of Québec respirologists (per capita) may partly explain this higher rate of BCT. However, Canada's geography seems to moderate the correlation between the number of tests and respirologists: there were fewer tests per respirologist in the West (i.e., Alberta, Saskatchewan, and British Columbia, with the exclusion of Manitoba). Other variables-including numbers of allergists and internists, location of completion of medical training, population, percentage of urban population, population density, and health expenditures-also correlate with the number of tests, albeit more weakly. Moreover, the current interpretation of these findings alongside the ratios of BCTs to asthmatics, as illustrated in Figure 5, suggest that Québec and Ontario aside, Canada may be under-utilizing BCT.

\section{How many tests?}

Published reports document that between roughly 60\% [28] and 90\% [32] of adults show normal spirometry despite respiratory symptoms. Assuming Canada manages asthma in congruence with the asthma guidelines [2], the proportion of asthmatics getting BCT should loosely match the percentages of these reports. Between 2000 and 2014 it is estimated (see Figure 5) that the equivalent of nearly $60 \%$ of asthmatics went through BCT in Québec, whereas in Ontario this number was just a hair over $30 \%$. These two provinces contrast with the rest of Canada that all lie under the $25 \%$ threshold. In addition, medical specialists are more likely to recommend PFT compared with general practitioners [23, $24,42]$. This paper shows that the use of BCT relates to the number of respirologists, allergists, and internists, but not to the number of general practitioners; however, most Canadian provinces seem to shy away from BCT. Overall, this trend echoes an overarching tendency to discount the guidelines of the Canadian Asthma Consensus: for example, to confirm the diagnosis of asthma objectively given that almost $50 \%$ of patients reported having never received a lung function test [21].

Ignoring asthma guidelines may have important consequences. One study [10] estimated that the improper diagnosis of asthma due to a lack of objective PFT could cost Canadians more than $\$ 275$ million over a 50-year period. There is also some evidence that provinces differ in their misdiagnosis rates. Data from a recent survey of 10 Canadian cities [12, 22] suggest that over-diagnosis of asthma may be higher in western provinces (Manitoba, 49\%; British Columbia, 48\%; Alberta, 44\%) and lower in eastern provinces (Ontario, 39\%; Nova Scotia, 29\%; Québec, 24\%). ${ }^{2}$ Furthermore, this regional distribution seems to follow the general pattern identified earlier regarding the relation between respirologists and BCT (Figure 4). These findings raise the possibility that regional variation in BCT translates to similar variations in misdiagnosis rates.

\section{Potential reasons for variation in BCT in Canada}

Why provinces differ in their use of BCT remains unclear; a wide array of complex factors and interactions is likely at play (see Table 1 for examples). For instance, to obtain financial compensation in Québec, workers need to confirm the diagnosis of occupational asthma with objective tests [43, 44]. Moreover, Québec reportedly possesses a higher concentration of occupational and exercise-induced asthma specialists (Dr. Sandra D. Anderson, written communication, July 2016; Dr. Alan Kaplan, written communication, July 2016), and individuals with occupational asthma may undergo BCT multiple times, typically 4-10 times (Dr. André Cartier, oral communication, June and December, 2016). Counterintuitively, the number of pulmonary function laboratories per province and the reimbursed amount physicians receive for conducting or interpreting the test hardly relates to BCT rates (see the figure in Supplementary File $5^{1}$ ).

\footnotetext{
${ }^{2}$ Misdiagnosis rates by province were computed by averaging data from the 10 Canadian cities surveyed in the study and using the same methodology as the authors (number of participants who completed the study algorithm/number of people for whom the diagnosis of asthma was ruled out on serial testing).
} 


\section{FIGURE 1}

Total number of medical claims for bronchial challenge testing for 2000-2001 to 2014-2015. This presentation, rather than using a logarithmic scale, illustrates how the provinces of Québec and Ontario stand out from the rest. $L=$ Newfoundland and Labrador, $\mathbf{P}=$ Prince Edward Island, $\mathbf{N}=$ New Brunswick, $\mathbf{Q}=$ Québec, $\mathbf{O}=$ Ontario, $\mathbf{M}=\mathbf{M a n i t o b a}, \mathbf{S}=\mathbf{S a s k a t c h e w a n}$, A = Alberta, $B=$ British Columbia.

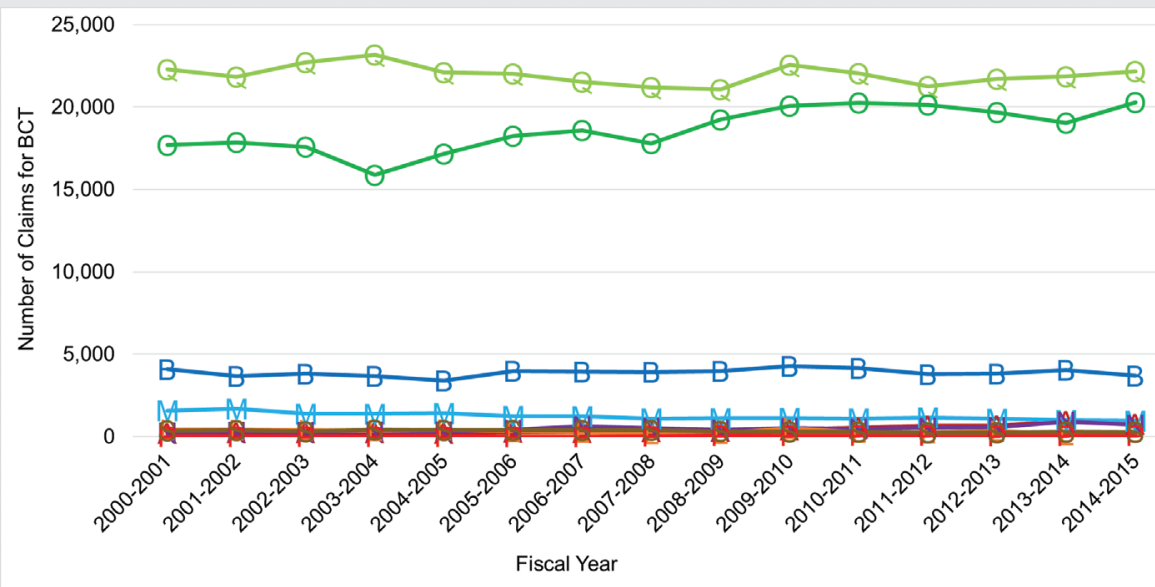

TABLE 1

Correlation analyses of number of BCT claims, per capita, for the Canadian provinces

\begin{tabular}{|c|c|c|c|c|}
\hline Measure (by number of BCT claims, per capita, 2000-2014) & $\begin{array}{l}\text { Degrees of freedom } \\
\qquad(n-2)\end{array}$ & Correlation (r) & $p$ & $\begin{array}{l}\text { Bootstrapped } 95 \% \\
\text { confidence interval }\end{array}$ \\
\hline Respirologists [36], per capita; Model 1 & 132 & $0.582^{* * *}$ & $<0.001$ & {$[0.421,0.716]$} \\
\hline Respirologists, per capita (excluding AB, BC, and SK); Model 2 & 87 & $0.930^{\star * *}$ & $<0.001$ & {$[0.883,0.958]$} \\
\hline Allergists [36], per capita; Model 1 & 132 & $0.718^{* * *}$ & $<0.001$ & {$[0.649,0.785]$} \\
\hline Allergists, per capita (excluding AB, BC, and SK); Model 2 & 87 & $0.747^{* * *}$ & $<0.001$ & {$[0.656,0.838]$} \\
\hline General internists [36], per capita; Model 1 & 132 & $0.210^{*}$ & 0.015 & {$[0.105,0.328]$} \\
\hline General internists, per capita (excluding AB, BC, and SK); Model 2 & 87 & 0.186 & 0.080 & {$[0.050,0.325]$} \\
\hline General practitioners [36], per capita & 132 & -0.071 & 0.418 & {$[-0.181,0.045]$} \\
\hline General practitioners, per capita (excluding AB, BC, and SK); Model 2 & 87 & -0.170 & 0.112 & {$[-0.310,-0.031]$} \\
\hline MD degree received from foreign university [35] ${ }^{\mathrm{a}}$ & 132 & $-0.533^{* * *}$ & $<0.001$ & {$[-0.642,-0.403]$} \\
\hline Estimated population with asthma $[38]^{\mathrm{b}}$, per capita & 88 & 0.052 & 0.623 & {$[-0.090,0.193]$} \\
\hline Population [34] & 132 & $0.626^{\star * *}$ & $<0.001$ & {$[0.576,0.688]$} \\
\hline Percentage of urban population $[39]^{c}$ & 25 & $0.451^{*}$ & 0.018 & {$[0.227,0.664]$} \\
\hline Population density $[40]^{c}$ & 25 & $0.628^{\star * *}$ & $<0.001$ & {$[0.442,0.865]$} \\
\hline Health expenditures [41], per capita & 132 & $-0.183^{*}$ & 0.034 & {$[-0.330,-0.023]$} \\
\hline Public health expenditures, per capita & 132 & $-0.233^{* *}$ & 0.007 & {$[-0.374,-0.078]$} \\
\hline Private health expenditures, per capita & 132 & -0.003 & 0.974 & {$[-0.180,0.179]$} \\
\hline Administration expenditures, per capita & 132 & $-0.254^{\star *}$ & 0.003 & {$[-0.330,-0.179]$} \\
\hline Capital expenditures, per capita & 132 & -0.037 & 0.668 & {$[-0.205,0.140]$} \\
\hline Drug expenditures, per capita & 132 & 0.147 & 0.090 & {$[-0.050,0.321]$} \\
\hline Hospital expenditures, per capita & 132 & $-0.326^{* * *}$ & $<0.001$ & {$[-0.447,-0.186]$} \\
\hline Other health spending expenditures, per capita & 132 & $-0.184^{*}$ & 0.033 & {$[-0.311,-0.043]$} \\
\hline Other institutional expenditures, per capita & 132 & 0.100 & 0.248 & {$[-0.046,0.239]$} \\
\hline Other professional expenditures, per capita & 132 & -0.083 & 0.341 & {$[-0.232,0.088]$} \\
\hline Physician expenditures, per capita & 132 & -0.101 & 0.247 & {$[-0.270,0.093]$} \\
\hline "Public health" expenditures, per capita & 132 & $-0.429^{\star * *}$ & $<0.001$ & {$[-0.546,-0.295]$} \\
\hline
\end{tabular}

${ }^{*} p<0.05 ;{ }^{* *} p<0.01 ;{ }^{* * *} p<0.001$.

Note: This table does not present an exhaustive list. Bold text indicates a statistically significant difference. $A B=A l b e r t a ; B C=B r i t i s h$ Columbia; SK = Saskatchewan.

${ }^{a}$ These data from the Canadian Institute for Health Information's Supply, Distribution and Migration of Canadian Physicians includes all physicians (family medicine and specialists). For the correlations, the percentage of physicians who obtained their medical training outside Canada was used.

${ }^{b}$ Estimated population with asthma was only available for years 2003, 2005, and 2007-2014.

${ }^{c}$ Percentages of urban population and population density were only available from the 2001, 2006, and 2011 censuses.

Several asthma specialists interviewed also pointed out that the medical culture in Québec emphasizes the objective confirmation of asthma diagnosis (Dr. Jean-Luc Malo, written communication, May 2016; Dr. André Cartier, oral communication, June 2016; Dr. Ronald Olivenstein, written communication, May 2016; Dr. James G. Martin, written communication, July 2015; Ms. Sandra Di Palma, written communication, July 2015). Concurrently, outside of Québec, practitioners may disparage the value and clinical utility of BCT (Dr. Donald W. Cockcroft, 


\section{FIGURE 2}

Number of bronchial challenge tests per 1000 population in relation to the number of respirologists per 10,000 population for each province, 2000-2014. L = Newfoundland and Labrador, $P=$ Prince Edward Island, $N=$ New Brunswick, $Q=Q$ Qébec, $\mathrm{O}=$ Ontario, $\mathbf{M}=$ Manitoba, $\mathbf{S}$ = Saskatchewan, $\mathbf{A}=$ Alberta, $\mathrm{B}=$ British Columbia.

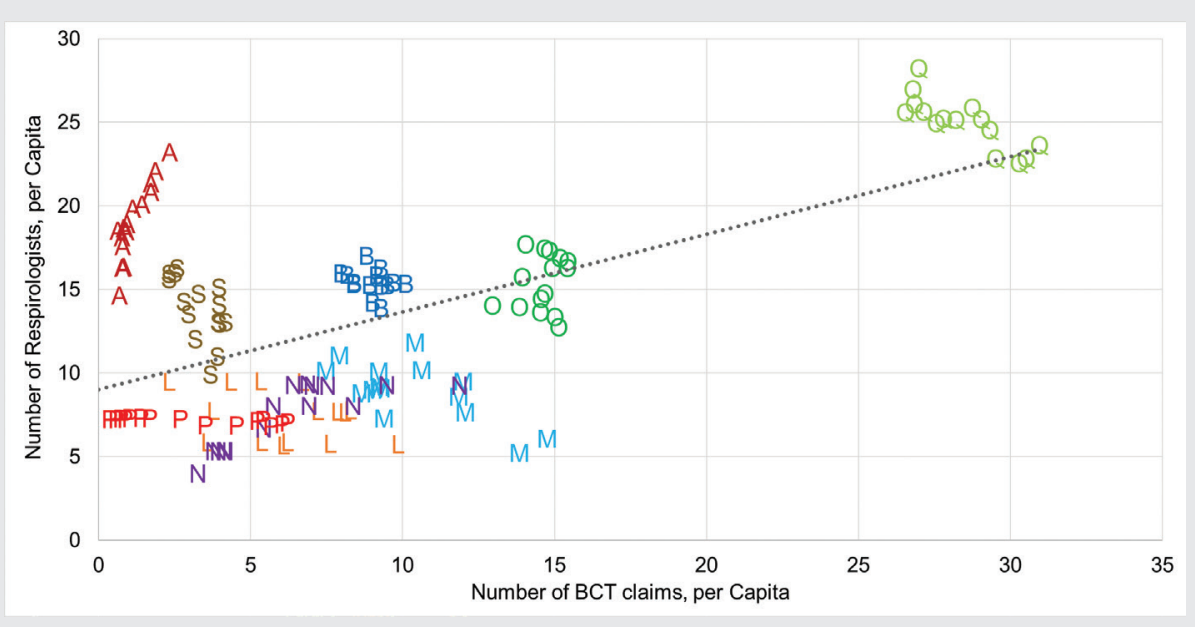

\section{FIGURE 3}

Provinces sorted by magnitude of the difference between the average number of bronchial challenge tests per 1000 population (in blue) and the average number of respirologists per 10,000 population (in orange), 2000-2014. Provinces to the left indicate greater positive difference, while provinces to the right indicate greater negative difference.

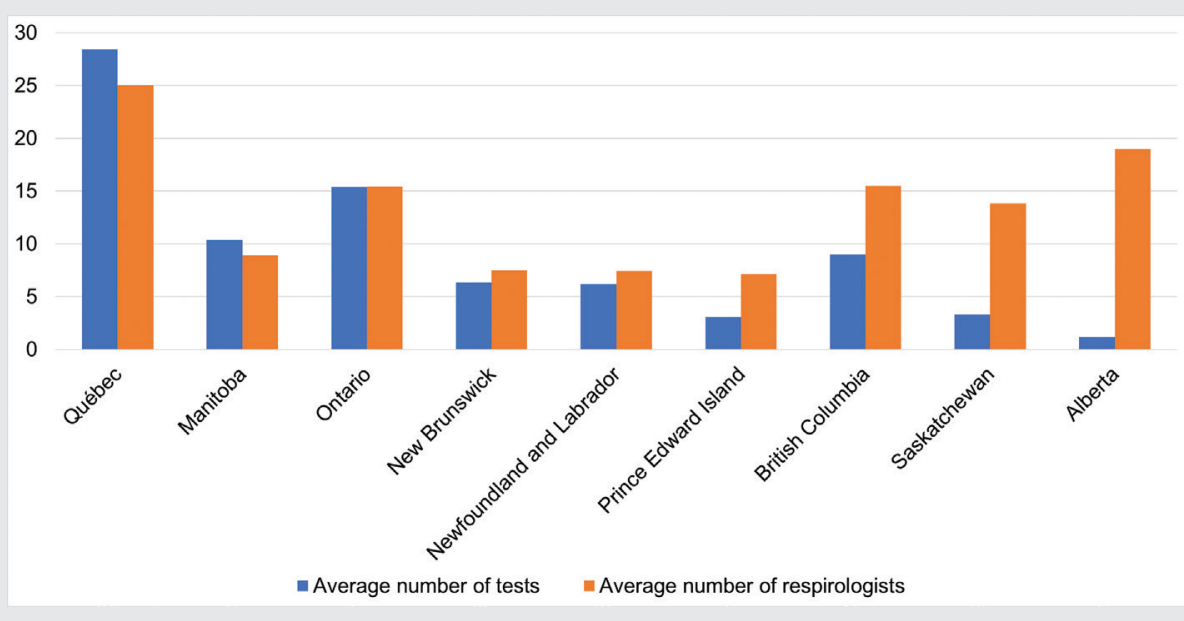

written communication, July 2015)-although this does not mean they necessarily disagree with the objective confirmation of asthma using alternative methods such as spirometry and peak flow measurement. As a case in point, the use of spirometry depends on whether physicians believe it necessary to pose an accurate diagnosis [24]. This paper shows that completing medical training outside of Canada relates to fewer BCT claims; Québec physicians are correspondingly much more likely to obtain their medical training in Canada than physicians from other provinces [35]. Perhaps the influence of prominent Canadian experts (e.g., Freddy Hargreave [45, 46] and his protégées [47, 48], and the Montréal group, including the Meakins-Christie Laboratories [49]) lingers as a factor still governing the higher BCT rates in eastern Canada and Québec today.

\section{Limitations}

The following overarching caveats apply to this study. (i) Nova Scotia and Newfoundland and Labrador provided partial or complete omissions of data (see Supplementary file $2^{1}$ ). (ii) The term "BCT" is hardly uniform across provinces (see Supplementary file $1^{1}$ ). (iii) Although a reasonable approximation, medical claims may under-estimate the true number of tests-for instance, in Alberta, several groups with alternative payment plans do not always report their activities fully (Dr. Stephen K. Field, written communication, August 2016; Mr. David Onyschuk, written communication, September 2016). Similarly, in Québec, physicians working in children's hospitals sometimes have alternative payment plans that prevent them from claiming BCT (Dr. Jacques-Édouard Marcotte, written communication, August 2016; Dr. Larry Lands, 


\section{FIGURE 4}

Difference between average number of bronchial challenge tests per 1000 population and average number of respirologists per 10,000 population, 2000-2014 (see Figure 3). Red indicates a greater negative difference, while green indicates no difference or a positive difference. Figure produced with Heatmapper.ca online software available at http://www.heatmapper. ca/geomap/ [37].

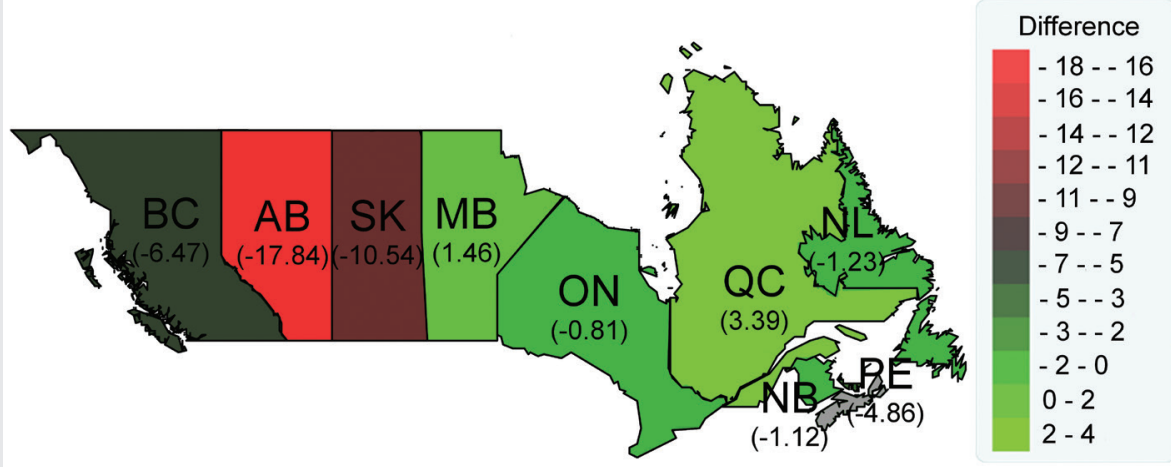

\section{FIGURE 5}

Total number of bronchial challenge tests for 2000-2014, by province, divided by the estimated number of individuals with asthma in 2014 (estimation by Statistics Canada). The $50 \%$ (green) and $25 \%$ (red) thresholds are only for reference.

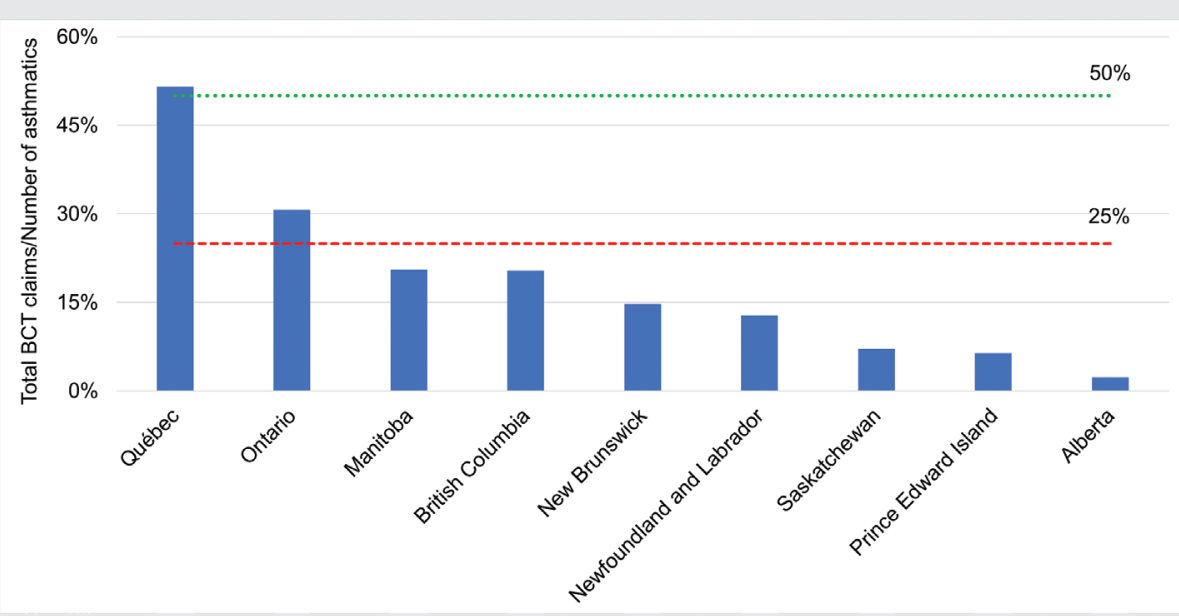

written communication, May 2016). Under-reporting of medical claims may occur in other provinces as well.

Important limitations also apply to the procedure for estimating the number of asthmatics who had BCT. First, provinces with a greater proportion of individuals followed for occupational asthma (e.g., Québec) may have inflated numbers, assuming these individuals undergo BCT more than once. Furthermore, the total number of tests only covers the past 15 years, whereas asthmatics may have undergone BCT before this period, hence this analysis likely under-estimates the actual number of asthmatics who received BCT. However, the procedure used estimates from Statistics Canada for the number of people who report having received a diagnosis of asthma by their physician [38]-these individuals may or may not have received BCT. This last limitation may actually provide more support for this estimation because including cases in which BCT excluded the diagnosis of asthma would further decrease the percentages of suspected asthmatics who had BCT, and reinforce the hypothesis that most provinces under-use BCT. And yet, this procedure provides but a rough estimation of the number of asthmatics who received $\mathrm{BCT}$.

\section{CONCLUSION}

This paper shows substantial interprovincial variations in the use of BCT. These findings expand our understanding of the diagnosis of asthma in Canada by highlighting the critical role of respirologists and the moderating effect of geographic region. A tentative analysis also suggests that certain provinces may be under-prescribing BCT, thereby increasing risks for misdiagnosis of asthma and associated health care costs. Overall, this investigation complements earlier research on the misdiagnosis of asthma $[10-18,21-24]$ and contributes to a more systematic understanding of the use of objective testing in asthma. Future research should address the possibility of under-reporting in the current study, as well as the reliance on a rough approximation to determine how many individuals diagnosed with asthma underwent BCT. To detect and address the misdiagnosis of asthma specifically, the respiratory medicine 
community would stand to benefit, over and beyond documenting PFT, from a more precise and thorough assessment of clinicians' adherence to the Canadian guidelines when diagnosing and managing asthma.

\section{FUNDING}

This project was funded by the Canada Research Chair program, Discovery and Discovery Acceleration Supplement grants from NSERC, the Canadian Institutes of Health Research, and the BIAL Foundation (to Amir Raz); and by the Arts Undergraduate Research Internship Award from the Faculty of Arts at McGill University, the Graduate Excellence Fellowship in Mental Health Research from the Department of Psychiatry at McGill University, and by the Joseph Armand Bombardier Canada Graduate Scholarship - Master's (to Rémi Thériault).

\section{COMPETING INTERESTS}

The authors have no conflicts of interest to disclose.

ACKNOWLEDGEMENT: We would like to thank the following individuals for providing feedback and sharing their opinions with us: Drs. André Cartier, James Martin, Ronald Dandurand, Ron Olivenstein, Jean-Luc Malo, and Alan Kaplan. We would also like to thank members of the Raz Lab who reviewed previous versions of this manuscript. Part of this material is based on data and information provided by the Canadian Institute for Health Information. However, the analyses, conclusions, opinions and statements expressed herein are those of the authors and not necessarily those of the Canadian Institute for Health Information.

\section{REFERENCES}

1. Global Initiative for Asthma (GINA). Global strategy for asthma management and prevention: Updated 2018. 2018. Available at: www. ginasthma.org. Accessed April 6, 2018.

2. Lougheed MD, Lemiere C. Ducharme FM, et al. Canadian Thoracic Society 2012 guideline update: Diagnosis and management of asthma in preschoolers, children and adults. Can Respir J 2012;19(2): 127-64. doi: 10.1155/2012/635624.

3. Lemière $\mathrm{C}$, Bai $\mathrm{T}$, Balter $\mathrm{M}$, et al. Adult asthma consensus guidelines update 2003. Can Respir J 2004;11(Suppl A): 9A-18A. doi: 10.1155/ 2004/271362.

4. British Thoracic Society, Scottish Intercollegiate Guidelines Network. British guideline on the management of asthma: A national clinical guideline: Revised 2016. Available at: https://www.brit-thoracic.org.uk. Accessed April 6, 2018.

5. Busse W, Boushey H, Camargo C, Evans D, Foggs M, Janson S. Expert panel report 3: Guidelines for the diagnosis and management of asthma. Washington, DC: US Department of Health and Human Services, National Heart Lung and Blood Institute; 2007. p. 1-417.

6. Tarlo SM, Boulet L-P, Cartier A, et al. Canadian Thoracic Society guidelines for occupational asthma. Can Respir J 1998;5(4): 289-300. doi: 10.1155/1998/587580.

7. Brigham EP, West NE. Diagnosis of asthma: Diagnostic testing. Int Forum Allergy Rhinol 2015;5(Suppl 1):S27-S30. doi: 10.1002/alr.21597.

8. Kaplan A, Stanbrook M. Must family physicians use spirometry in managing asthma patients?. YES Can Fam Physician 2010;56(2): 126-8.

9. Birnbaum S, Barreiro TJ. Methacholine challenge testing: Identifying its diagnostic role, testing, coding, and reimbursement. Chest 2007;131(6): 1932-5. doi: 10.1378/chest.06-1385.

10. Pakhale S, Sumner A, Coyle D, Vandemheen K, Aaron S. (Correcting) misdiagnoses of asthma: A cost effectiveness analysis. BMC Pulm Med 2011;11(1): 1. doi: 10.1186/1471-2466-11-27

11. Aaron SD, Vandemheen KL, Boulet LP, et al. Overdiagnosis of asthma in obese and nonobese adults. Can Med Assoc J 2008;179(11): 1121-31. doi: $10.1503 /$ cmaj.081332.

12. Aaron SD, Vandemheen KL, FitzGerald JM, et al. Reevaluation of diagnosis in adults with physician-diagnosed asthma. JAMA 2017;317(3): 269-79. doi: 10.1001/jama.2016.19627.

13. Lindensmith J, Morrison D, Deveau C, Hernandez P. Overdiagnosis of asthma in the community. Can Respir J 2004;11(2): 111-16. doi: $10.1155 / 2004 / 276493$.
14. Looijmans-van den Akker I, van Luijn K, Verheij T. Overdiagnosis of asthma in children in primary care: A retrospective analysis. Br J Gen Pract 2016;66(644): e152-7. doi: 10.3399/bjgp16X683965.

15. Yang CL, Simons E, Foty RG, Subbarao P, To T, Dell SD. Misdiagnosis of asthma in schoolchildren. Pediatr Pulmonol 2017;52(3): 293-302. doi: 10.1002 ppul.23541.

16. van Huisstede A, Cabezas MC, van de Geijn G-JM, et al. Underdiagnosis and overdiagnosis of asthma in the morbidly obese. Respir Med 2013;107(9): 1356-1364. doi: 10.1016/j.rmed.2013.05.007.

17. van Schayck CP, van der Heijden FMMA, van den Boom G, Tirimanna PRS, van Herwaarden CLA. Underdiagnosis of asthma: Is the doctor or the patient to blame? The DIMCA project. Thorax 2000;55(7): 562-5. doi: $10.1136 /$ thorax.55.7.562.

18. Enright PL, McClelland RL, Newman AB, Gottlieb DJ, Lebowitz MD. Underdiagnosis and undertreatment of asthma in the elderly. Chest 1999;116(3): 603-13. doi: 10.1378/chest.116.3.603.

19. Stanbrook MB, Kaplan A. The error of not measuring asthma. Can Med Assoc J 2008;179(11): 1099-100. doi: 10.1503/cmaj.081665.

20. D'Urzo AD. Must family physicians use spirometry in managing asthma patients?. No Can Fam Physician 2010;56(2): 127-9

21. Chapman KR, Ernst P, Grenville A, Dewland P, Zimmerman S. Control of asthma in Canada: failure to achieve guideline targets. Can Respir J 2001; 8(Suppl A):35A-40A. doi: 10.1155/2001/245261.

22. Aaron SD, Vandemheen K, Boulet LP. et al. Diagnosis and over-diagnosis of asthma in Canadian adults. In Conference Abstract presented at American Thoracic Society 2016 International Conference; May 17; San Francisco, CA; 2016. p. A4561.

23. Gershon AS, Victor JC, Guan J, Aaron SD, To T. Pulmonary function testing in the diagnosis of asthma: A population study. Chest 2012;141(5): 1190-6. doi: 10.1378/chest.11-0831.

24. O'Dowd LC, Fife D, Tenhave T, Panettieri RA Jr. Attitudes of physicians toward objective measures of airway function in asthma. Am J Med 2003;114(5): 391-6. doi: 10.1016/S0002-9343(03)00007-X.

25. Gjevre JA, Hurst TS, Taylor-Gjevre RM, Cockcroft DW. The American Thoracic Society's spirometric criteria alone is inadequate in asthma diagnosis. Can Respir J 2006;13(8): 433-7. doi: 10.1155/2006/198940.

26. Kaplan AG, Balter MS, Bell AD, Kim H, Mclvor RA. Diagnosis of asthma in adults. Can Med Assoc J 2009;181(10): E210-20. doi: 10.1503/ cmaj.080006.

27. Smith AD, Cowan JO, Filsell S, et al. Diagnosing asthma: Comparisons between exhaled nitric oxide measurements and conventional tests. Am J Respir Crit Care Med 2004;169(4): 473-8. doi: 10.1164/rccm. 200310-1376OC.

28. Ferguson GT, Enright PL, Buist AS, Higgins MW. Office spirometry for lung health assessment in adults: A consensus statement from the national lung health education program. Chest 2000;117(4): 1146-61. doi: 10.1378/chest.117.4.1146.

29. Nair SJ, Daigle KL, DeCuir P, Lapin CD, Schramm CM. The influence of pulmonary function testing on the management of asthma in children. J Pediatr 2005;147(6): 797-801. doi: 10.1016/j.jpeds.2005.07.023.

30. Bacharier LB, Strunk RC, Mauger D, White D, Lemanske RF, Sorkness CA. Classifying asthma severity in children. Am J Respir Crit Care Med 2004;170(4): 426-32. doi: 10.1164/rccm.200308-1178OC.

31. Griffiths C, Feder G, Wedzicha J, Foster G, Livingstone A, Marlowe GS. Feasibility of spirometry and reversibility testing for the identification of patients with chronic obstructive pulmonary disease on asthma registers in general practice. Respir Med 1999;93(12): 903-8. doi: 10.1016/ S0954-6111(99)90057-4.

32. Schneider A, Gindner L, Tilemann L, et al. Diagnostic accuracy of spirometry in primary care. BMC Pulm Med 2009;9: 31. doi: 10.1186/ 1471-2466-9-31

33. Merger D, Tanguay C, Bussières J-F. Test de bronchoprovocation à la méthacholine et exposition professionnelle. Bull Inform Toxicol 2012; 28(2): $16-26$

34. Table 051-0001 - Estimates of population, by age group and sex for July 1, Canada, provinces and territories, annual (persons unless otherwise noted). CANSIM (database); 2000-2014. Available at: http://www5. statcan.gc.ca/cansim/a26?lang=eng\& retrLang=eng\& id $=0510001 \& \&$ pattern $=\&$ stByVal $=1 \& p 1=1 \& p 2=37 \&$ tabMode $=$ data $T a b l e \& c s i d=$ (Accessed August 29, 2016).

35. Supply, distribution and migration of Canadian physicians: Data tables. 2010-2014. Available at: https://secure.cihi.ca/estore/productSeries. htm?pc =PCC34 (Accessed November 11, 2016).

36. Number of physicians by province/territory and specialty, Canada. CMA Masterfile (database); 2000-2014. Available at: https:// 
www.cma.ca/En/Pages/physician-historical-data.aspx (Accessed August 30, 2016).

37. Babicki S, Arndt D, Marcu A, et al. Heatmapper: Web-enabled heat mapping for all. Nucleic Acids Res 2016;44(W1): W147-53. doi: 10.1093/ nar/gkw419.

38. Table 105-0501 - Health indicator profile, annual estimates, by age group and sex, Canada, provinces, territories, health regions (2013 boundaries) and peer groups, occasional. CANSIM (database); 2003-2014. Available at: http://www5.statcan.gc.ca/cansim/a26?lang=eng\& retrLang= eng\& $\mathrm{id}=1050501 \& \&$ pattern $=\& \mathrm{stByVal}=1 \& \mathrm{p} 1=1 \& \mathrm{p} 2=37 \& \mathrm{tabMode}=$ dataTable\&csid= (Accessed August 29, 2016).

39. Population, urban and rural, by province and territory (Canada). 200 1, 2006, 2011. Available at: http://www.statcan.gc.ca/tablestableaux/sum-som/101/cst01/demo62b-eng.htm (Accessed November 15, 2016).

40. Census Profile - Comprehensive download files for a selected geographic level: CSV or TAB. 2001, 2006, 2011. Available from: http://www12. statcan.gc.ca/census-recensement/2011/dp-pd/prof/details/download-telecharger/comprehensive/comp-csv-tab-dwnld-tlchrgr. cfm? Lang=E\#tabs2011 (Accessed November 15, 2016).

41. National Health Expenditure Trends. 2000-2014. Available from: https://www.cihi.ca/en/spending-and-health-workforce/spending/ national-health-expenditure-trends (Accessed November 15, 2016).
42. Diette GB, Skinner EA, Nguyen TTH, Markson L, Clark BD, Wu AW. Comparison of quality of care by specialist and generalist physicians as usual source of asthma care for children. Pediatrics 2001;108(2): 432-437. doi: 10.1542 /peds.108.2.432.

43. Malo J-L. Compensation for occupational asthma in Quebec. Chest 1990;98(5 Suppl): 236S-9S.

44. Malo JL, Dewitte JD, Cartier A, Ghezzo H. The Quebec system of compensation for occupational asthma: Description, effectiveness and cost. Rev Mal Respir 1993;10(4): 313.

45. O’Byrne P, Nair P, Frederick E. Hargreave Can Respir J 2011;18(4): 193. doi: $10.1155 / 2011 / 517945$

46. Cockcroft DW, Frederick E. "Freddy" Hargreave, MB ChB, MD. Ann Allergy Asthma Immunol 2016;116(4): 271-273. doi: 10.1016/j.anai. 2016.02.007

47. Cockcroft DW, Killian DN, Mellon JJA, Hargreave FE. Bronchial reactivity to inhaled histamine: A method and clinical survey. Clin Exp Allergy 1977;7(3): 235-243. doi: 10.1111/j.1365-2222.1977.tb01448.x.

48. Hargreave FE, Nair P. The definition and diagnosis of asthma. Clin Exp Allergy 2009;39(11): 1652-1658. doi: 10.1111/j.1365-2222.2009. 03321.x.

49. Martin JG, Schwartzman K. Respiratory medicine and research at McGill University: A historical perspective. Can Respir J 2015;22(1): e4-e7. doi: $10.1155 / 2015 / 348180$. 